\title{
EL DERECHO A LA VIDA Y DEREGHO PENAL INTERNACIONAL: ¿LA REGULACIÓN ES COHERENTE?*
}

\author{
THE RIGHT TO LIFE AND INTERNATIONAL CRIMINAL LAW: \\ IS THE REGULATION COHERENT? ?** $^{* *}$
}

\author{
Javier DONDÉ MATUTE***
}

RESUMEN: El derecho a la vida es uno de los derechos humanos más importante; ha sido reconocido en todos los tratados de derechos humanos y a nivel nacional; su privación es sancionada penalmente. Sin embargo, en el derecho penal internacional no tiene la misma regulación que en las jurisdicciones nacionales, y tampoco tiene la misma importancia en comparación con otros derechos humanos, como la dignidad humana, el debido proceso y la igualdad racial.

Palabras clave: Derecho a la vida, derecho penal internacional, derechos humanos, homicidio, tortura, crímenes internacionales, terrorismo, ejecuciones extrajudiciales, desaparición forzada.
ABSTRACT: The right to life is one of the most important human rights, it has been recognized in all human rights treaties and on a national level, their breach is a criminal offence. Nonetheless, in International Criminal Law it doesn't have the same regulation that national jurisdictions and the same importance in contrast with others human rights such as human dignity, due process and racial equality.

Keyzerds: Right to life, international criminal law, human rights, homicide, torture, terrorism, extrajudicial executions, forced disappearance.

* Artículo recibido el 12 de julio de 2016 y aceptado para su publicación el 30 de enero de 2017.

** Publicado originalmente en inglés: "Right to Life and International Criminal Law: Is the regulation coherent?" en la Revista Iberoamericana de Derechos Humanos, núm. 4, 2009. Traducción realizada por Ivonne Karilu Muñoz García.

**** Profesor-investigador en el Instituto Nacional de Ciencias Penales, y miembro del Sistema Nacional de Investigadores.javier.donde@inacipe.gob.mx.

Boletín Mexicano de Derecho Comparado nueva serie, año XLX, núm. 149, mayo-agosto de 2017, pp. 645-672

D. R. (C) 2017. UNAM, Instituto de Investigaciones Jurídicas. 
Esta revista forma parte del acervo de la Biblioteca Jurídica Virtual del Instituto de Investigaciones Jurídicas de la UNAM www.juridicas.unam.mx

Sumario: I. Introducción. II. Derecho internacional de los derechos humanos. III. Homicidio en derecho penal internacional. IV. Conclusión.

\section{INTRODUCGIÓN}

La vida es el derecho humano más importante. ${ }^{1} \mathrm{Si}$ esta declaración fuera cierta, las sanciones penales estarían vinculadas a conductas que la lesionan. ${ }^{2}$ Este es el caso en la mayoría de las jurisdicciones nacionales, pero ¿el derecho penal internacional (DPI) sigue esta tendencia? ${ }^{3}$

En este artículo se argumentará que el derecho a la vida (DAV), aunque ampliamente reconocido en el derecho internacional de los derechos humanos (DIDDHH) como un derecho humano fundamental, está inadecuadamente protegido en el DPI. A pesar de que otros derechos humanos, como la dignidad humana, el debido proceso y la igualdad racial están protegidos por diferentes crímenes internacionales, el homicidio (principal medio para proteger la vida a través de una sanción penal) no está regulado en el DPI, en el Estatuto de la Corte Penal Internacional (ECPI) o en algún otro tratado. Aunque otros crímenes como la tortura o la desaparición forzada de personas son objeto de obligaciones convencionales para perseguirlos internamente por parte de los Estados, no hay una regulación similar para la protección a la vida.

Este trabajo abordará dos posibles explicaciones: un cambio en el sistema de valores internacionales en el que el DAV ya no es tan importante como se pensaba, o un vacío en el derecho internacional, en el cual el homicidio debe ser considerado como un crimen internacional a través de un tratado, igual que la tortura y la desaparición forzada.

Para evaluar dichas alternativas, el presente artículo analizará el estado actual del DIDDHH y del DPI. En la primera parte, el objetivo no será describir el DAV en el ámbito internacional, sino tratar de compro-

1 Meron, Theodor, "On a Hierarchy of International Human Rights", American fournal of International Law, vol. 80, 1986. Sería difícil afirmar que hay otros derechos humanos más importantes que el derecho a la vida y la protección contra la tortura.

2 Ramcharan, B. G., "The Right to Life", Netherlands International Law Review, vol. XXX, 1983, pp. 327-329. Resalta 37 aspectos donde el derecho a la vida podría estar mejor protegido por el derecho internacional.

3 A los efectos del presente artículo, DPI se referirá a la regulación de sanciones penales a través de fuentes internacionales. 
Esta revista forma parte del acervo de la Biblioteca Jurídica Virtual del Instituto de Investigaciones Jurídicas de la UNAM

bar la importancia que tiene frente a otros derechos humanos protegidos por sanciones penales y establecer qué tipo de violaciones han sido identificadas, con el fin de determinar el alcance de dichas sanciones. En la segunda parte, se considerarán los crímenes internacionales que regulan la privación de la vida, con el propósito de establecer en qué grado (si lo hay) el DAV es la esencia de dicha prohibición.

En la sección uno se estudiará el DAV en el DIDDHH. En esta parte del estudio será esencial considerar la jurisprudencia en el tema de los tribunales regionales de derechos humanos, en un esfuerzo para determinar si el sistema de valores internacionales ha cambiado, dándole un papel menor al DAV frente a otros derechos humanos.

Esta sección será esencial para determinar el alcance actual del DAV, lo que ayudará a establecer el bien exacto que debe ser protegido por el DPI, asumiendo que este derecho humano aún es lo suficientemente importante para ser protegido a través de una sanción penal.

En la sección dos, se considerará al DPI. La base para ello serán los crímenes donde la privación de la vida es el núcleo del actus reus (como el homicidio). En este sentido, serán analizados aquellos crímenes derivados del ECPI: genocidio, crímenes de lesa humanidad y crímenes de guerra. Adicionalmente, será necesario examinar los crímenes que no forman parte de la jurisdicción de la Corte Penal Internacional (CPI), pero que tienen un tratado base, como ciertas formas de terrorismo. Lo anterior es necesario, ya que usualmente el terrorismo involucra la pérdida de la vida, por lo que parecería que este crimen protege el DAV. Asimismo, se evaluará la regulación de las ejecuciones extrajudiciales, sumarias o arbitrarias (EESA), con la finalidad de determinar su alcance y valor como un crimen internacional efectivo en la protección del DAV.

La sección tres se ocupará del análisis de las actuales tendencias, como se describe en las secciones anteriores. Una parte importante de esta explicación será la comparación de los crímenes que están internacionalmente regulados pero que aparentemente protegen derechos humanos de menor o igual valor.

Una vez que dichos factores sean analizados, el presente artículo buscará dar una explicación al alcance actual del DAV como un derecho humano y su relación con el DPI.

Finalmente, es importante mencionar lo que no está incluido en este artículo. Es bien sabido que el alcance del DAV ha evolucionado a tra- 
Esta revista forma parte del acervo de la Biblioteca Jurídica Virtual del Instituto de Investigaciones Jurídicas de la UNAM

vés de la jurisprudencia. La Corte Interamericana de Derechos Humanos (Corte IDH) ha sido especialmente prolífica en este tema al expandir el alcance del DAV más allá de la mera privación de la vida para incluir el derecho a una vida digna. ${ }^{4}$ Sin embargo, este estudio solamente se enfoca en la simple privación de la vida y no en la calidad de la misma. Esto lleva a la siguiente aclaración: en lo que concierne a la responsabilidad estatal, el DIDDHH provee obligaciones positivas, esto es, acciones que el Estado debe realizar para asegurar que el DAV no sea violado y que sus nacionales tengan un estándar mínimo de vida. ${ }^{5}$ Nuevamente, este aspecto queda fuera del alcance del presente estudio, que está limitado a la tipificación de la conducta. Es decir, a las consecuencias penales derivadas del derecho internacional una vez que la violación ha ocurrido. En resumen, aunque dichos aspectos son importantes y relevantes en la discusión actual del DAV, no forman parte del presente estudio.

\section{DEREGHO INTERNAGIONAL DE LOS DERECHOS HUMANOS}

El objetivo de esta sección es establecer el alcance actual del DAV a través de la jurisprudencia de los tribunales regionales. Se les verá en lo individual, pero toda vez que tienen que ser considerados en su conjunto como posturas representativas de las tendencias internacionales, se llegará a una conclusión general e inductiva.

El DAV forma parte de cada tratado de derechos humanos. Su marco jurídico básico consiste en tres partes. Primera, los tratados reconocen la existencia de dicho derecho con frases como "el derecho a la vida es inherente a la persona humana". ${ }^{6}$ Ocasionalmente, habrá alguna referencia a la obligación de proteger el derecho a través de la ley. ${ }^{7}$ Segunda, se hace una excepción del DAV con relación a la pena de muerte, al disponer que

4 Corte IDH, caso Comunidad Indigena Yakye Axa v. Paraguay, fondo reparaciones y costas, sentencia del 17 de junio de 2005, serie C, núm. 125, párrs. 162-176.

5 Corte IDH, caso Comunidad Indígena Sawhoyamaxa v. Paraguay, fondo, reparaciones y costas, sentencia del 29 de marzo de 2006, serie C, núm. 146, párrs. 150-155.

6 Pacto Internacional de Derechos Civiles y Políticos, artículo 6 (1) y Carta Árabe de Derechos Humanos, artículo 5 (a).

7 Convenio Europeo de Derechos Humanos, artículo 2 (1) y Convención Americana sobre Derechos Humanos, artículo 4 (1). 
Esta revista forma parte del acervo de la Biblioteca Jurídica Virtual del Instituto de Investigaciones Jurídicas de la UNAM

sólo pueda imponerse por un tribunal competente, de forma no arbitraria y si así lo prevé la ley. ${ }^{8}$ Aunque se pueden encontrar otras limitaciones, éstas son las comunes a todos los tratados. Tercera, en todos los casos el DAV es considerado un derecho inderogable. ${ }^{9}$

Este es el marco jurídico internacional básico del DAV. ${ }^{10}$ Todos los tratados universales y regionales de derechos humanos incorporan este derecho. Hay limitaciones análogas, tales como la imposición de la pena de muerte bajo ciertas condiciones y la prohibición total de la privación arbitraria de la vida, pero también la mayoría de los tratados consideran el DAV como inderogable. A primera vista, esta posición es contradictoria, al menos para los presentes propósitos, dado que las excepciones a dicho derecho parecen indicar que en algunas instancias o bajo ciertas condiciones el derecho puede tener excepciones. Sin embargo, se considera lo suficientemente importante, que no debe ser derogado bajo ninguna circunstancia.

En un esfuerzo por determinar el actual significado y alcance de este derecho, es importante observar la jurisprudencia de los diferentes tribunales de derechos humanos.

\section{Tribunal Europeo de Derechos Humanos}

El caso emblemático con relación al DAV es McCann y otros v. Reino Unido. ${ }^{11}$ En Gibraltar, un grupo de sospechosos de terrorismo fueron abatidos a tiros por fuerzas de seguridad, quienes sospechaban que pudieran detonar un carro bomba. En este caso, se analizaron los principios básicos

8 Pacto Internacional de Derechos Civiles y Políticos, artículo 6 (1); Carta Árabe de Derechos Humanos, artículos 5 (b) y 6o.; Convenio Europeo de Derechos Humanos, artículo 2 (1) y Convención Americana sobre Derechos Humanos, artículo 4 (2).

9 Pacto Internacional de Derechos Civiles y Políticos, artículo 4o.; Convenio Europeo de Derechos Humanos, artículo 15 (2) y Convención Americana sobre Derechos Humanos, cfr. Carta Árabe de Derechos Humanos, artículo 4o. El DAV no aparece como un derecho inderogable en la Carta.

10 Esto también puede ser llamado stricto sensu derecho a la vida y puede incluir otros aspectos. Véase en general Przetacznik, F., "The Right to Life as a Basic Human Right", Revue Des Droit de l'Homme Human Rights Fournal, vol. IX, 1976.

11 TEDH, McCann and others v. United Kingdom, Application 18984/91, Judgment, 27 de septiembre de 1995 . 
Esta revista forma parte del acervo de la Biblioteca Jurídica Virtual del Instituto de Investigaciones Jurídicas de la UNAM

del DAV y se hizo una consideración de la importancia de este derecho humano. ${ }^{12}$

Antes de iniciar su análisis, el Tribunal Europeo de Derechos Humanos (TEDH) enfatizó la importancia del DAV:

Se debe tomar en cuenta que como disposición (art. 2), que no sólo salvaguarda el derecho a la vida sino también establece las condiciones cuando la privación de la vida puede estar justificada, el articulo 2 (art. 2) se ubica como uno de los preceptos más importantes en la Convención, de hecho uno que, en tiempos de paz, no admite derogación bajo el Artículo 15 (art. 15). Junto con el artículo 3 (art. 15+3) de la Convención, consagra uno de los valores básicos de las sociedades democráticas que forman el Consejo de Europa. Como tal, sus disposiciones deben ser interpretadas estrictamente. ${ }^{13}$

Por consiguiente, dado que el artículo 2o. considera que el uso de la fuerza debe ser "absolutamente necesario", el estándar impuesto es más estricto que el requerido por la frase "necesario en una sociedad democrática", utilizado en otros artículos de la Convención. ${ }^{14}$

Una manifestación adicional a la importancia otorgada a este derecho es el hecho de que el TEDH enfatizó que proteger la vida de la población civil justificaba la detención ilegal de los sospechosos de terrorismo. Por lo tanto, sostuvo:

El Tribunal se limita a observar en este sentido, que el peligro a la población de Gibraltar - base de los alegatos del Gobierno en este caso - al no prevenir su entrada debe ser considerado para compensar las posibles consecuencias de no tener suficiente evidencia para justificar su detención y juicio. En su opinión, o las autoridades sabían que no había bomba en el carro - lo

12 Para una explicación detallada de la jurisprudencia en materia de derecho a la vida véase Ovey, Clare y White, Robin, facobs \& White, The European Convention on Human Rights, New York, Oxford University Press, 2006, pp. 591 y Ni Aolain, Fionnuala, "The Evolving Jurisprudence of the European Convention Concerning the Right to Life", 19 Netherlands Quaterly of Human Rights, vol. 19, núm. 1, 2001, p. 21; véase también Kara E, Irwin, "Prospects for Justice: the Procedural Aspect of the Right to Life under the European Convention on Human Rights and its Applications to Investigations of Northern Ireland's Bloody Sunday", Fordham International Law fournal, vol. 22, 1999, para una discusión sobre los requisitos de investigación de la protección del derecho a la vida.

13 TEDH, McCann and others v. United Kingdom, cit. párr. 147 (citas omitidas).

14 Ibidem, párr. 149. 
Esta revista forma parte del acervo de la Biblioteca Jurídica Virtual del Instituto de Investigaciones Jurídicas de la UNAM

que el Tribunal ya descartó - o hubo un grave error de cálculo por parte de los responsables de controlar la operación. Como resultado, el escenario estaba preparado para que el tiroteo fatal, teniendo en cuenta las evaluaciones de inteligencia que se habían hecho, era una posibilidad previsible, sino una probabilidad. ${ }^{15}$

Existen tres elementos que el TEDH consideró para establecer la importancia del DAV: su estatus como un derecho que no admite derogación, estándares más altos para sus excepciones y su prioridad sobre otros derechos humanos, al menos, respecto a detenciones arbitrarias. Sin embargo, hay otros puntos interesantes a considerar.

El TEDH en McCann consideró que el DAV es al menos igual de importante que la prohibición contra la tortura y otros tratos o penas inhumanos o degradantes, prohibición ampliamente aceptada que conlleva sanciones penales. ${ }^{16}$ Esta premisa ha sido confirmada en casos como Houhvanainen ${ }^{17}$, Akpinar and Altun ${ }^{18}$ y Yüksel Erdogan and others. ${ }^{19}$

Por otro lado, existen varios casos donde el TEDH ha mencionado que un aspecto importante en la protección del DAV es el establecimiento de sanciones penales cuando dicho derecho es amenazado. Lo anterior se remonta a la sentencia de Osman, que establece la obligación de sancionar penalmente todas las violaciones al DAV. ${ }^{20}$ Sin embargo, esta afirmación ha sido matizada en otros casos. En Öneryildiz, los demandantes se quejaban de la muerte de nueve de sus familiares a causa de una explosión accidental de metano en un basurero, el TEDH reconoció que las sanciones penales sólo deberían ser aplicadas cuando la privación de la vida sea intencional, por lo que determinó:

15 Ibidem, párr. 205 (citas omitidas); véase también TEDH, Nachova and Others v. Bulgaria, Application 43577/98 y 43579/98, Judgment, 6 de julio de 2005, párr. 95, donde se sostuvo que llevar a cabo un arresto legal no puede justificar poner en riesgo la vida de una persona.

16 Véase abajo la sección F.

17 TEDH, Houhvanainen v. Finland, Application 57389/00, Judgment, 13 de marzo de 2007, párr. 92.

18 TEDH, Akpinar and Altun v. Turkey, Application 56760/00, Judgement, 27 de febrero de 2007, párr. 47.

19 TEDH, Yüksel Erdogan and Others v. Turkey, Application 57049/00, Judgement, 15 de febrero de 2007 párr. 84.

20 TEDH, Osman v. the United Kingdom, Application 87/1997/871/1083, Judgment, 28 de octubre de 1998, párr. 115 (citas omitidas) (énfasis añadido). 
Esta revista forma parte del acervo de la Biblioteca Jurídica Virtual del Instituto de Investigaciones Jurídicas de la UNAM

...si la violación al DAV o a la integridad física no se causó intencionalmente, la obligación positiva de imponer un "sistema judicial efectivo" no requiere necesariamente que un procedimiento penal se lleve a cabo en cada caso y puede ser satisfecha si hubo recursos disponibles a las víctimas, ya sea civiles, administrativos e incluso disciplinarios. ${ }^{21}$

Existen otros dos aspectos importantes para este estudio donde se expande la aplicación del DAV. En Öneryildiz, el TEDH también plantea la regla de que no sólo los organismos públicos pueden violar este derecho. Sin embargo, este principio usualmente ha sido aplicado a casos donde las autoridades no han realizado una investigación exhaustiva, por lo que no se ha determinado si la violación fue causada por un agente del Estado. ${ }^{22}$

Adicionalmente, el TEDH también ha considerado casos donde en realidad no ha ocurrido privación de la vida, ya que la sola amenaza es suficiente para violar el artículo 2o. ${ }^{23}$ Dentro de estos casos, los más relevantes para la presente discusión son aquellos donde la pérdida de vida siguió a un caso de privación de la libertad, como en la desaparición forzada. ${ }^{24}$

\section{Corte Interamericana de Derechos Humanos}

Como su contraparte europea, la Corte IDH ha enfatizado la importancia del DAV en sus primeras decisiones. ${ }^{25} \mathrm{El}$ estándar de uso de la

21 TEDH, Öneryildiz v. Turkey, Application 48939/99, Judgement, 30 de noviembre de 2004, párr. 92; véase también TEDH, Tarariyeva v. Russia, Application 4353/03, Judgement, 14 de diciembre de 2006. Una vez más se enfatizó que sólo los casos intencionales deben recaer exclusivamente en el ámbito del derecho penal, como en el caso de negligencia médica.

22 TEDH, Kasa v. Turkey, Reports of Fudgements and Decisions 1998-VI, Judgement, 2 de septiembre de 1998, y TEDH, Kaya and others v. Turkey, Application 4451/02, Judgement, 24 de octubre de 2006.

23 TEDH, Ilhan v. Turkey, Application 22277/93, Judgement, 27 de junio de 2000, párr. 75. Véanse también los casos citados en el párrafo 79.

24 TEDH, Timurtas v. Turkey, Application 23531/94, Judgement, 13 de junio de 2000, párr. 83; véase también TEDH, Tas v. Turkey, Application 24396/94, Judgement, 14 de noviembre de 2000; y TEDH, Gongadze v. Ukraine, Application 34056/02, Judgement, 8 de noviembre de 2005.

25 Para un estudio exhaustivo del DAV en el sistema interamericano de derechos humanos véase Saavedra Alessandri, Pablo, "El derecho a la vida en la jurisprudencia de la 
Esta revista forma parte del acervo de la Biblioteca Jurídica Virtual del Instituto de Investigaciones Jurídicas de la UNAM

fuerza cuando sea "absolutamente necesario" adoptado en McCann fue seguido por la Corte IDH en Centro Retén de Catia, que aborda el uso excesivo de la fuerza por custodios de la prisión. ${ }^{26}$

La Corte IDH tiene un gran número de casos que abordan el DAV, que se remontan a Niños de la Calle, donde se determinó que el Estado participó en el secuestro y ejecución de niños de la calle. En este caso, la Corte sostuvo:

El derecho a la vida es un derecho humano fundamental, cuyo goce es un prerrequisito para el disfrute de todos los demás derechos humanos. De no ser respetado, todos los derechos carecen de sentido. En razón del carácter fundamental del derecho a la vida, no son admisibles enfoques restrictivos del mismo. En esencia, el derecho fundamental a la vida comprende, no sólo el derecho de todo ser humano de no ser privado de la vida arbitrariamente, sino también el derecho a que no se le impida el acceso a las condiciones que le garanticen una existencia digna. Los Estados tienen la obligación de garantizar la creación de las condiciones que se requieran para que no se produzcan violaciones de ese derecho básico y, en particular, el deber de impedir que sus agentes atenten contra él. ${ }^{27}$

La naturaleza fundamental del DAV ha sido desarrollada a tal grado que la Corte IDH considera como norma de jus cogens la prohibición de ejecuciones extrajudiciales. En este sentido, en Hermanos Gómez Paquiyauri estableció "Sobre el particular, la Corte ha señalado que cuando existe un patrón de violaciones a los derechos humanos, entre ellas ejecuciones extrajudiciales impulsadas o toleradas por el Estado, contrarias a jus cogens, se genera un clima incompatible con una efectiva protección del derecho a la vida". ${ }^{28}$

Corte Interamericana de Derechos Humanos", en Martín, Claudia et al. (coord.), Derecho internacional de los derechos humanos, México, 2004, p. 281.

26 Corte IDH, caso Montero Aranguren y otros (Retén de Catia) v. Venezuela, excepción preliminar, fondo, reparaciones y costas, sentencia del 5 de julio de 2006, serie C, núm. 150, párr. 68.

27 Corte IDH, caso de los "Niños de la Calle" (Villagrán Morales y otros) v. Guatemala, fondo, sentencia del 19 de noviembre de 1999, serie C, núm. 63, párr. 144; véase también Corte IDH, caso Myrna Mack Chang v. Guatemala, fondo, reparaciones y costas, sentencia del 25 de noviembre de 2003, serie C, núm. 101, párr. 152. Agregando que es un derecho inalienable.

28 Corte IDH, caso de los Hermanos Gómez Paquiyauri v. Perú, fondo, reparaciones y costas, sentencia del 8 de julio de 2004, serie C, núm. 110, párr. 128. 
Esta revista forma parte del acervo de la Biblioteca Jurídica Virtual del Instituto de Investigaciones Jurídicas de la UNAM www.juridicas.unam.mx

Esta idea ha sido más desarrollada, al mencionar que este derecho tiene que ser protegido por el Estado a través de sanciones penales, entre otros medios: “...los Estados deben tomar las medidas necesarias, no sólo para prevenir y castigar la privación de la vida como consecuencia de actos criminales, sino también prevenir las ejecuciones arbitrarias por parte de sus propias fuerzas de seguridad". ${ }^{29}$

La Corte IDH también ha expresado su preocupación por las personas especialmente vulnerables, como los menores en prisión, ${ }^{30}$ miembros de comunidades indígenas que han sido abandonados por el Estado ${ }^{31}$ y los enfermos mentales. ${ }^{32}$ En estos casos se ha determinado que la obligación del Estado de proteger el DAV se intensifica.

En relación con los crímenes internacionales, la Corte IDH consistentemente ha sostenido que los casos de desaparición forzada pueden involucrar una amenaza al DAV. En Velázquez Rodríguez se consideró que la desaparición forzada involucra violaciones graves a los derechos humanos. ${ }^{33}$

Sin embargo, en estas circunstancias, el DAV sólo se infringe cuando la pérdida de la vida es resultado de la detención y del trato sufrido:

La práctica de desapariciones, en fin, ha implicado con frecuencia la ejecución de los detenidos, en secreto y sin fórmula de juicio, seguida del ocultamiento del cadáver con el objeto de borrar toda huella material del crimen y de procurar la impunidad de quienes lo cometieron, lo que significa una brutal violación del derecho a la vida, reconocido en el artículo 4o. de la Convención... ${ }^{34}$

29 Corte IDH, caso Fuan Humberto Sánchez v. Honduras. excepción preliminar, fondo, reparaciones y costas, sentencia del 7 de junio de 2003, serie C, núm. 99, párr. 99

30 Corte IDH, caso "Instituto de Reeducación del Menor" v. Paraguay, excepciones preliminares, fondo, reparaciones y costas, sentencia del 2 de septiembre de 2004, serie C, núm. 112 , párr. 160 .

31 Corte IDH, caso Comunidad Indígena Yakye Axa v. Paraguay, fondo, reparaciones y costas, sentencia del 17 de junio de 2005, serie C, núm. 125, párr. 162.

32 Corte IDH, caso Ximenes Lopes v. Brasil, sentencia del 4 de julio de 2006, serie C, núm. 149, párr. 148.

33 Corte IDH, caso Velásquez Rodríguez v. Honduras, fondo, sentencia del 29 de julio de 1988, serie C, núm. 4, párr. 156.

34 Ibidem, párr. 157; véase también Corte IDH, caso Godinez Cruz v. Honduras, fondo, sentencia del 20 de enero de 1989, serie C, núm. 5, párr. 165. En este caso, se identificó un patrón de desapariciones forzadas en el Estado. 
Esta revista forma parte del acervo de la Biblioteca Jurídica Virtual del Instituto de Investigaciones Jurídicas de la UNAM

Esta regla ha cambiado, ya que las desapariciones forzadas por sí mismas son consideradas amenazas al DAV. Así, después de reafirmar lo dicho en Velásquez Rodríguez, la Corte IDH sostuvo en Blake: "la desaparición forzada o involuntaria constituye una de las más graves y crueles violaciones de los derechos humanos, pues no sólo produce una privación arbitraria de la libertad sino que pone en peligro la integridad personal, la seguridad y la propia vida del detenido". ${ }^{35}$

Respecto a las sanciones penales, la Corte IDH ha considerado que los derechos inderogables, incluido el DAV, no están sujetos a "disposiciones de amnistía, las disposiciones de prescripción y el establecimiento de excluyentes de responsabilidad que pretendan impedir la investigación y sanción de los responsables de las violaciones graves de los derechos humanos tales como... las ejecuciones sumarias, extralegales o arbitrarias...". ${ }^{36}$

Adicionalmente, al análisis de las leyes de autoamnistía, dicho razonamiento ha sido reafirmado en los casos de actividades paramilitares, donde se ha establecido que los juicios derivados de serias violaciones a derechos humanos, incluido el DAV, no sólo se deben enfocar en los "perpetradores del hecho", sino también en los "responsables intelectuales", especialmente en casos donde el Estado está involucrado. ${ }^{37}$

\section{Consideraciones generales respecto al derecho internacional de los derechos humanos}

En su conjunto, la jurisprudencia de derechos humanos parece haber matizado la importancia del DAV. En realidad, este derecho consistentemente ha sido negado en casos de imposición legal de la pena de muerte. Esto en sí, es suficiente para sugerir que el DAV no es tan importante como se piensa comúnmente.

Sin embargo, hay más razones para poner en duda la importancia de este derecho. La más obvia es la falta de una declaración general de los ór-

35 Corte IDH, caso Blake v. Guatemala, fondo, sentencia del 24 de enero de 1998, serie C, núm. 36, párr. 66 .

36 Corte IDH, caso Barrios Altos v. Perú, fondo, sentencia del 14 de marzo de 2001, serie C, núm. 75, párr. 41.

37 Corte IDH, caso de la Masacre de Pueblo Bello v. Colombia, sentencia del 31 de enero de 2006, serie C, núm. 140, párr. 143. 
Esta revista forma parte del acervo de la Biblioteca Jurídica Virtual del Instituto de Investigaciones Jurídicas de la UNAM

ganos de derechos humanos, al señalar que el DAV es una norma perentoria, que limita sus pronunciaciones a casos de EESA. Aun cuando estos órganos han subrayado la naturaleza inderogable de este derecho, ha sido para enfatizar la interpretación estricta de sus excepciones, pero de esto no se desprende ninguna obligación de imponer sanciones penales.

La imposición de sanciones penales por la violación de este derecho se ha limitado a los agentes estatales. Esta afirmación puede encontrarse en el hecho de que dichos órganos de derechos humanos dejan la investigación de violaciones de este derecho al sistema penal interno, al obligar a los Estados a crear mecanismos eficientes para la aplicación del derecho penal. En los casos donde los particulares pueden haber provocado la muerte, la jurisprudencia se enfoca en la investigación llevada a cabo por los Estados, y encontró que hubo una violación al DAV cuando se hizo de forma inadecuada, y no por la muerte en sí.

Aunque más adelante se aborden las particularidades en la regulación del DAV, es importante señalar que existen suficientes excepciones y diferencias en el DIDDHH para sugerir que dicho derecho jamás ha sido tan importante como parecería. A pesar de que se siga catalogando más alto que la mayoría de los derechos, sólo las privaciones de la vida causadas por agentes estatales (incluidas las organizaciones paramilitares) son de interés internacional. Por lo que sólo estos casos son tipificados.

En este sentido, al analizar las fuentes del DPI en la siguiente sección, dicho criterio debe ser considerado como parte de la tipificación de las violaciones del DAV en los instrumentos actuales o en futuras propuestas.

\section{HOMICIDIO EN DERECHO PENAL INTERNAGIONAL}

En esta sección se analizará la regulación de la privación de la vida en el DPI. Se dividirá en dos partes: el estudio del homicidio u otras privaciones de vida como parte de la jurisdicción material de la CPI y otros tratados que pugnan por el castigo de estas acciones.

Queda fuera del alcance de este artículo un análisis detallado de las definiciones penales. El objetivo de esta sección es subrayar los elementos particulares y las circunstancias requeridas para que la privación de la 
Esta revista forma parte del acervo de la Biblioteca Jurídica Virtual del Instituto de Investigaciones Jurídicas de la UNAM

vida sea considerada un crimen internacional. ${ }^{38}$ Si bien es cierto que los tratados analizados no abordan específicamente las violaciones al DAV, no se puede ignorar que la privación de la vida es considerada en varios casos, aunque bajo ciertas circunstancias. Sin embargo, dado que la postura del presente artículo es que ese derecho necesita un tratado universal que abarque los homicidios de interés internacional, es necesario profundizar en el marco existente para establecer que actualmente existe un vacío en la criminalización del DAV.

\section{Genocidio}

El artículo 6o. del ECPI contempla que se entenderá por genocidio: a) matanza de miembros del grupo; b) lesión grave a la integridad física o mental de los miembros del grupo; $c$ ) sometimiento intencional del grupo a condiciones de existencia que hayan de acarrear su destrucción física, total o parcial; $d$ ) medidas destinadas a impedir nacimientos en el seno del grupo; e) traslado por la fuerza de niños del grupo a otro grupo con la intención de destruir total o parcialmente a un grupo nacional, étnico, racial o religioso como tal.

En primer lugar, debe hacerse notar que sólo el inciso (a) menciona la posible privación de la vida. Las otras conductas describen casos donde la vida de los individuos que componen el grupo protegido no está en riesgo. Aun en el caso del inciso (c), los miembros del grupo experimentan una reducción en sus necesidades básicas para una vida digna, pero en sí no implica la muerte de los individuos. ${ }^{39}$

Es más, todos estos actos, incluidos los de la sección (a), tienen que ser cometidos con una intención específica (dolus especialis). Por lo que si este requisito no se cumple no puede haber genocidio tal y como lo contempla el tipo penal, a pesar de que haya ocurrido una privación de la vida, con el mens rea requerido. Esto muestra el hecho de que el genocidio está

38 Mettraux, Guénaël, "International Crimes and Ad Hoc Tribunals", BHRLR, vol. 6, 2005. (Para un análisis exhaustivo de los crímenes internacionales desarrollados por la jurisprudencia de los tribunales de Naciones Unidas para la Ex-Yugoslavia y Ruanda).

39 Elementos de los Crímenes, U.N. Doc. PCNICG/2000/1/Add.2 (2000), artículo 6 (c) Genocidio mediante sometimiento intencional a condiciones de existencia que hayan de acarrear su destrucción física. Ninguno de los cinco elementos que conforman dicho crimen requieren la privación de la vida, como tal. 
Esta revista forma parte del acervo de la Biblioteca Jurídica Virtual del Instituto de Investigaciones Jurídicas de la UNAM

diseñado para proteger a ciertos grupos humanos, mas no a los miembros individuales. ${ }^{40}$ Por lo tanto, tomar la vida de una persona no es la esencia de la prohibición, sino una cuestión incidental. ${ }^{41}$

\section{Crimenes de lesa humanidad}

En el artículo 7 (1) del ECPI hay dos tipos penales que describen la privación de la vida o al menos la amenaza a ésta, el asesinato y el exterminio como crímenes de lesa humanidad. ${ }^{42}$ El exterminio "comprenderá la imposición intencional de condiciones de vida, entre otras, la privación del acceso a alimentos o medicinas, entre otras, encaminadas a causar la destrucción de parte de una población". ${ }^{43}$

Mientras que el asesinato como crimen de lesa humanidad es evidente, el exterminio es menos claro, ya que a primera vista se podría in-

40 Gil, Alicia, El genocidio y otros crímenes internacionales, Valencia, Centro Francisco Tomás y Valiente UNED-Alzira Valencia, 1999, p. 142, véase también Alonzo-Maizlish, David, "In Whole or in Part: Group Rights, the Intent Element of Genocide, and the 'Quantitative Criterion'”, New Kork University Law Review, vol. 77, 2002. Afirmando que el "genocidio" se basa en la existencia de un grupo internacionalmente reconocido.

41 TPIY, Prosecutor v. Sikirica et al., Judgement on defence motions to acquit, IT-95-8-T, 3 de septiembre de 2001, párr. 89: La prueba debe demostrar que es el grupo el que ha sido seleccionado como objetivo y no meramente personas específicas dentro del grupo. Ello es el significado de la frase "como tal" en el encabezado. Mientras que son los individuos los que constituyen las víctimas de la mayoría de los crímenes, la víctima final del genocidio es el grupo, aunque su destrucción necesariamente implica la comisión de crímenes contra sus miembros; es decir, contra las personas que pertenecen a ese grupo". Véase Saul, Ben, "Was the Conflict in East Timor 'Genocide' and why does it matter?", Melbourne fournal of International Law, vol. 2, 2001. Menciona que en realidad el genocidio ofende al individuo y al grupo, aunque este autor reconoce que en derecho internacional el genocidio es el más atroz de los dos.

42 La CPI, al analizar el asesinato como crimen de lesa humanidad, únicamente desarrolla los elementos del tipo penal. Véase CPI, Prosecutor v. Germain Katanga, Judgment pursuant to article 74 of the Statute, Trial Chamber II, 7 march 2014, ICG-01/04-01/073436, párrs. 765-782, CPI, Prosecutor v. Jean-Pierre Bemba Gombo, Judgment pursuant to article 74 of the Statute, 21 march 2016, ICG-01/05-01/08-3343, párrs. 87-90; CPI, Prosecutor v. Bosco Ntaganda, Decision Pursuant to Article 61(7)(a) and (b) of the Rome Statute on the Charges of the Prosecutor Against Bosco Ntaganda, Pre-Trial Chamber II, 9 june 2014, ICG-01/04-02/06-309, párrs. 38-44.

43 Estatuto de la Corte Penal Internacional, A/CONF.183/9 (en adelante ECPI) artículo 7 (2)(b). 
Esta revista forma parte del acervo de la Biblioteca Jurídica Virtual del Instituto de Investigaciones Jurídicas de la UNAM

ferir que no tiene lugar ninguna pérdida de la vida. Sin embargo, de los elementos de los crímenes ${ }^{44}$ se desprende que este resultado es requerido conforme a la definición penal.

No obstante, ambas conductas requieren que sean cometidas como parte de un ataque sistemático o generalizado, lo que significa que los casos individuales de privación de la vida no son crímenes de lesa humanidad. ${ }^{45}$ Esta afirmación se confirma por la definición del ECPI de "ataque contra la población civil": "se entenderá como 'ataque contra la población civil' una línea de conducta que implique la comisión múltiple de actos mencionados en el párrafo 1 contra una población civil, de conformidad con la política de un Estado o de una organización de cometer ese ataque...". ${ }^{46}$

Si bien se puede argumentar que los actos mencionados no tienen que ser del mismo tipo, un solo asesinato (o caso de exterminio) tiene que haberse cometido como parte de un ataque; es decir, debe estar acompañado por otros actos descritos en dicha disposición para que un crimen de lesa humanidad ocurra, excluyendo los actos aislados, por lo que el asesinato (o exterminio) por sí sólo no es un crimen de lesa humanidad.

Adicionalmente, la definición de ataque en contra de la población requiere que la conducta sea cometida con un objetivo específico: la promoción de una política. Esto significa que el asesinato (o exterminio) cometido por otra razón no constituirá un crimen de lesa humanidad, aun si no es un incidente aislado, ya que no se configuraría otro elemento del ataque.

En esencia, el DAV no está efectivamente protegido por este crimen internacional, ya que a pesar de que una muerte puede ser causada para que ocurra un crimen de lesa humanidad, se deben probar todos los elementos contextuales. La complejidad de estos elementos hace difícil castigar a alguien por haber causado la muerte bajo este concepto, dejando una laguna enorme en su regulación.

44 Elementos de los crímenes, op. cit., artículo 7 (1)(b) Crimen de lesa humanidad de exterminio, "1. Que el autor haya dado muerte, a una o más personas, incluso mediante la imposición de condiciones de existencia destinadas deliberadamente a causar la destrucción de parte de una población. 2. Que la conducta hay consistido en una matanza de miembros de una población civil o haya tenido lugar como parte de esa matanza".

45 Ibidem, artículo 7o. Crímenes de lesa humanidad, introducción, párr. 2. La naturaleza sistemática o generalizada de los actos forman parte del actus reus del crimen.

46 ECPI, artículo 7 (2)(a). 
Esta revista forma parte del acervo de la Biblioteca Jurídica Virtual del Instituto de Investigaciones Jurídicas de la UNAM www.juridicas.unam.mx

DOI: http://dx.doi.org/10.22201/iij.24484873e.2017.149.11353

\section{Crímenes de guerra}

El caso de los crímenes de guerra es más complicado, debido al hecho de que el artículo 8o. del ECPI incluye un gran número de tipos penales que implican la privación de la vida o la amenaza al DAV. ${ }^{47}$ Sin embargo, esta protección legal tiene ciertas limitaciones. ${ }^{48}$

El artículo 8 (2)(a) que criminaliza las grandes violaciones a los Convenios de Ginebra de 1949, entre ellas "homicidio intencional", está limitado a aquellas personas (o bienes) protegidos por dichos tratados. Por consiguiente, sólo las vidas de civiles y prisioneros de guerra están protegidas. Lo mismo aplica a aquellos crímenes contemplados en el artículo 8 (2)(c), que penaliza las violaciones al Artículo 3 Común de los Convenios de Ginebra.

Por otro lado, los apartados (b) y (d) contemplan una serie de crímenes de guerra que involucran amenaza o violación al DAV de personas diferentes a las protegidas por los Convenios de Ginebra, incluidas en algunos casos a los combatientes. Sin embargo, estas disposiciones están sujetas a otra limitante: la existencia de un conflicto armado (sea de índole internacional o no internacional). Así, mientras que una limitante es removida para estos casos, otra toma su lugar. Por lo tanto, el DAV no está adecuadamente protegido por los crímenes de guerra.

Estas limitaciones tienen sentido, ya que la protección del DAV no es el objetivo perseguido por el derecho internacional humanitario. Dichas normas buscan minimizar los efectos de la guerra, especialmente en relación con aquellas personas (o bienes) que no forman parte de las hostilidades. ${ }^{49}$

47 Para una discusión de la relación entre el derecho internacional humanitario y el derecho a la vida véase Paust, Jordan, "The Right to Life in Human Rights Law and the Law of War", Saskatchewan Law Review, vol. 65, 2002.

48 La CPI, al analizar el homicidio como crimen de guerra únicamente desarrolla los elementos del tipo penal. Véase CPI, Prosecutor v. Germain Katanga, Judgment pursuant to article 74 of the Statute, 7 march 2014, ICG-01/04-01/07-3436, párr. 783-794; CPI; Prosecutor v. Fean-Pierre Bemba Gombo, Judgment pursuant to article 74 of the Statute, 21 march 2016, ICG-01/05-01/08-3343, párrs. 91-97; CPI, Prosecutor v. Bosco Ntaganda, Decision Pursuant to Article 61(7)(a) and (b) of the Rome Statute on the Charges of the Prosecutor Against Bosco Ntaganda, Pre-Trial Chamber II, 9 june 2014, ICG-01/04-02/06-309, párrs. 38-44.

49 Detter, Ingrid, The Law of War, 2a. ed., Cambridge, Cambridge University Press, 2000, pp. 156-160.

D. R. (C) 2017. UNAM, Instituto de Investigaciones Jurídicas, Boletín Mexicano de Derecho Comparado, núm. 149, pp. 645-672. 
Esta revista forma parte del acervo de la Biblioteca Jurídica Virtual del Instituto de Investigaciones Jurídicas de la UNAM

En consecuencia, el DAV es sólo un bien incidental protegido por los crímenes de guerra.

\section{Terrorismo}

A primera vista parecería obvio que el terrorismo, en todas sus formas, constituye una violación al DAV, entre otros valores. ${ }^{50}$ Sin embargo, aunque esto puede ser el caso en la práctica, dicha premisa no está sustentada en los tratados internacionales ni en las resoluciones de Naciones Unidas que tratan dicho tema, que tienden a enfatizar que el terrorismo puede ser cualquier acto que cause terror, con independencia de que la conducta real se haya cometido. ${ }^{51}$ Esta postura también está sustentada por la doctrina. ${ }^{52}$

De hecho, de los tratados internacionales que regulan las actividades terroristas, sólo los siguientes mencionan la privación de la vida en sus textos: ${ }^{53}$ Convenio Internacional para la Represión de los Atentados Terroristas cometidos con Bombas, Convención sobre la Prevención y el Castigo de Delitos contra Personas Internacionalmente Protegidas, Convención Internacional contra la Toma de Rehenes, y la Convención sobre la Protección Física de los Materiales Nucleares.

50 Travieso, Juan Antonio, Derechos humanos y derecho internacional, 2a. ed., Buenos Aires, Helista, 1996, pp. 508 y 509. Argumenta que el terrorismo es un crimen que, entre otros, protege la seguridad pública.

51 Asamblea General, Medidas para eliminar el terrorismo internacional, A/Res/49/60, 17 de febrero de 1995; véase también Asamblea General, Medidas para eliminar el terrorismo internacional, A/Res/55/158, 30 de enero de 2001 ("Actos criminales intencionales o calculados para provocar un estado de terror al público en general...".

52 Cassese, Antonio, International Criminal Law, New York, Oxford University Press, 2003, p. 125. La característica principal del terrorismo es la despersonalización de la víctima. Esto es, la víctima no es atacada por razones personales, sino con el fin de lograr otro objetivo; véase también Skubiszewski, Krysztof, "Definition of Terrorism", Israel Yearbook on Human Rights, vol. 19, 1989; también G, Gilbert, "The 'Law' and 'Transnational Terrorism”", Netherlands Yearbook of International Law, vol. XXVI, 1995, pp. 9 y 10. El crimen subyacente al acto terrorista no es importante, lo que es relevante es este causa terror en la población.

53 Para una vision general de estos tratados véase Trahan, Jennifer, “Terrorism Conventions: Existing Gaps and Different Approaches", New England International and Comparative Law Annual, vol. 8, 2002, p. 215. 
Esta revista forma parte del acervo de la Biblioteca Jurídica Virtual del Instituto de Investigaciones Jurídicas de la UNAM www.juridicas.unam.mx

Si bien ciertas referencias al homicidio aparecen en dichos tratados, su ámbito de aplicación e interés en proteger otros valores los hace mecanismos ineficientes para la protección penal del DAV.

En primer lugar, el Convenio Internacional para la Represión de los Atentados Terroristas cometidos con Bombas tipifica la detonación de un aparato explosivo en lugares públicos "con la intención de causar la muerte o graves lesiones corporales" ${ }^{54}$ Sin embargo, es sólo una de las conductas que se quiere sancionar, incluida la destrucción de la propiedad. El objetivo general de estas disposiciones penales no es la protección de la vida, sino el "mantenimiento de la paz y la seguridad internacionales y el fomento de las relaciones de amistad y buena vecindad y la cooperación entre Estados". ${ }^{55}$

En segundo lugar, la Convención sobre la Prevención y el Castigo de Delitos contra Personas Internacionalmente Protegidas tipifica el "homicidio" de una persona protegida, las cuales se limitan a representantes del Estado, incluidos jefes de Estado, ministros de relaciones exteriores, y diplomáticos en general. Por lo tanto, sólo la vida de ciertos individuos está protegida, y sólo en el interés del "mantenimiento de la paz y el fomento de las relaciones de amistad y cooperación entre Estados". ${ }^{56}$

En tercer lugar, a diferencia de los tratados anteriores, la Convención Internacional contra la Toma de Rehenes menciona en su preámbulo como uno de sus objetivos la protección el DAV, junto con los mismos intereses de paz y seguridad internacional y cooperación. Sin embargo, la toma de rehenes no constituye una violación del DAV por sí mismo. A pesar de que la amenaza a la vida de los rehenes está prevista en la Convención, sólo es considerada como un medio para lograr el objetivo último del terrorismo, presionar a un tercero para que actúe de cierta forma. ${ }^{57} \mathrm{~A}$ lo sumo, la toma de rehenes puede ser considerada como una amenaza a la vida, de la misma forma que la considera la desaparición forzada.

54 Convenio Internacional para la Represión de los Atentados Terroristas cometidos con Bombas, artículo 2 (1)(a)

55 Ibidem, preámbulo, párr. 1.

56 Convención sobre la Prevención y el Castigo de Delitos contra Personas Internacionalmente Protegidas, preámbulo, párr. 1.

57 Convención Internacional contra la Toma de Rehenes, artículo 1.1. La definición de toma de rehenes incluye la amenaza a la vida. 
Esta revista forma parte del acervo de la Biblioteca Jurídica Virtual del Instituto de Investigaciones Jurídicas de la UNAM

En cuarto lugar, la Convención sobre la Protección Física de los Materiales Nucleares es probablemente la convención internacional de terrorismo que criminaliza más de cerca las amenazas al DAV. En su preámbulo, estipula que no busca prohibir el uso pacífico de materiales nucleares, y reconoce que es un riesgo que está siempre presente. Por lo que es un deseo "prevenir los peligros que pueden plantear el uso o apoderamiento ilegal de materiales nucleares" ${ }^{58}$ Entre estos peligros se puede incluir la amenaza al DAV, aunque no fue mencionado expresamente en el preámbulo..$^{59}$

El artículo 7o. criminaliza la comisión intencionada de un acto (consistente en recibir, poseer, usar, entre otros), así como la amenaza de utilizar materiales nucleares que causen o es probable que causen la muerte. ${ }^{60}$ Por lo tanto, aunque el homicidio está tipificado por esta convención, sólo cubre los casos en los que los materiales nucleares son usados, por lo que el ámbito de aplicación y la protección del DAV están seriamente limitados.

Un esquema similar se puede encontrar en las convenciones regionales de terrorismo, donde el énfasis está en prohibir conductas que no están directamente descritas o definidas en estos tratados. La Convención Interamericana contra el Terrorismo, Convenio del Consejo de Europa para la Prevención del Terrorismo, Convención Árabe sobre la Supresión del Terrorismo refieren a los tratados de Naciones Unidas en la materia con el objetivo de identificar las conductas que son consideradas actos terroristas. ${ }^{61}$

Adicionalmente, la Convención Interamericana contra el Terrorismo no menciona que el DAV está protegido de una actividad terrorista. ${ }^{62} \mathrm{El}$ artículo 1o. menciona que el objeto de la convención es prevenir, castigar y eliminar el terrorismo, a través de cooperación estatal.

58 Convención sobre la Protección Física de los Materiales Nucleares, Preámbulo, párr. 3.

59 Convenio Internacional para la Represión de los Actos de Terrorismo Nuclear, artículo 2. Este tratado expresamente tipifica la posesión de material radiactivo o cualquier otro artefacto "con la intención de causar dolor".

60 Convención sobre la Protección Física de los Materiales Nucleares, artículo 7 (1).

61 Convención Interamericana contra el Terrorismo, artículo 2.1; Convenio del Consejo de Europa para la Prevención del Terrorismo, artículo 1.1; y Convención Árabe sobre la Supresión del Terrorismo, artículo 1.3.

62 Ibidem, preámbulo, párr. 2. 
Esta revista forma parte del acervo de la Biblioteca Jurídica Virtual del Instituto de Investigaciones Jurídicas de la UNAM

El Convenio del Consejo de Europa para la Prevención del Terrorismo dispone en su artículo 2o. que el terrorismo afecta derechos humanos, en particular el DAV, por lo que se deben adoptar medidas para su prevención.

Finalmente, la Convención Árabe sobre la Supresión del Terrorismo estipula "Deseosos de promover la cooperación mutua para la supresión de los delitos de terrorismo que suponen una amenaza a la seguridad y estabilidad de la Nación Árabe y ponen en peligro sus interés vitales". ${ }^{63}$

El único tratado regional de terrorismo que toma en consideración el DAV es la Convención para Prevenir y Combatir el Terrorismo de la Organización de la Unión Africana (UA), la cual dispone en su preámbulo: "CONVENCIDOS que el terrorismo constituye una seria violación a los derecho humanos y, en particular, los derechos de integridad física, vida, libertad y seguridad, e impide el desarrollo socioeconómico a través de la desestabilización de los Estados...". ${ }^{64}$ Adicionalmente, menciona que el terrorismo pone en peligro "la estabilidad y seguridad de los Estados".65

Las Naciones Unidas no ha sido clara en vincular el DAV con el terrorismo. La resolución de la Asamblea General en esta materia no considera esta conexión, ${ }^{66}$ a pesar del hecho de que el secretario general ha considerado en al menos un reporte dirigido a la Asamblea General, que el DAV está entre las violaciones que toman lugar en relación a actos terroristas. ${ }^{67}$

El Consejo de Seguridad también ha tomado parte de esta tendencia. Aunque el DAV ha sido considerado entre los derechos humanos y valores

63 Convención Árabe sobre la Supresión del Terrorismo, preámbulo, párr. 1.

64 Convención para Prevenir y Combatir el Terrorismo de la Unión Africana, preámbulo, párr. 9 .

65 Convención para Prevenir y Combatir el Terrorismo de la Unión Africana, preámbulo, párr. 5 .

66 Asamblea General, Estrategia global de las Naciones Unidas contra el terrorismo, A/ RES/60/288, 20 de septiembre de 2006.

67 Asamblea General, Informe del Secretario General; Unidos contra el terrorismo, recomendaciones para una estrategia global contra el terrorismo, A/60/825, 27 de abril de 2006, párr. 111. La libertad, la seguridad, el bienestar y el derecho a vivir sin temor, también fueron mencionados en el informe. 
Esta revista forma parte del acervo de la Biblioteca Jurídica Virtual del Instituto de Investigaciones Jurídicas de la UNAM

violados por actos terroristas, ${ }^{68}$ el énfasis ha sido en la paz y seguridad de la humanidad. ${ }^{69}$

Una vez más, los tratados internacionales que prohíben las actividades terroristas no contemplan el DAV en su núcleo. Su objetivo es proteger otros valores, como la paz y seguridad internacionales. Ciertamente, la vida es protegida como una cuestión incidental, pero no es la esencia de la penalización de las actividades terroristas.

\section{Ejecuciones extrajudiciales, sumarias o arbitrarias}

Se han presentado consecuencias legales más concretas por violaciones al DAV en el contexto de las EESA. Su marco jurídico está compuesto por una serie de resoluciones de la Asamblea General, el trabajo del Relator Especial en el tema, los Principios Relativos a una Eficaz Prevención e Investigación de las Ejecuciones Extralegales, Arbitrarias o Sumarias (Principios EESA) ${ }^{70}$ el Manual sobre la Prevención e Investigación Eficaces en las Ejecuciones Extralegales, Arbitrarias o Sumarias (Manual) ${ }^{71}$ y Prevención de las violaciones de derechos humanos cometidas con armas pequeñas y armas ligeras (Principios de Armas Pequeñas). ${ }^{72}$ Sin embargo, ninguno de estos instrumentos legales prevé los aspectos básicos proporcionados por otras violaciones de derechos humanos que también constituyen crímenes internacionales. En su lugar, se enfocan en medidas preventivas que no llegan a sanciones penales.

En primer lugar, si bien la Asamblea General ha reconocido la necesidad de "elaborar normas internacionales que aseguren la adopción de

68 Consejo de Seguridad, Amenazas a la pazy seguridad internacional causadas por actos terroristas, SC Res. 1438, 14 de octubre de 2002; Consejo de Seguridad, Amenazas a la paz y seguridad internacional causadas por actos terroristas, SC Res. 1440, 24 de octubre de 2002; Consejo de Seguridad, Consejo de Seguridad, Amenazas a la paz y seguridad internacional causadas por actos terroristas, SC Res. 1465, 14 de febrero de 2003; Consejo de Seguridad, Amenazas a la paz y seguridad internacional causadas por actos terroristas, SC Res. 1618, 4 de agosto de 2005.

69 Idem.

70 Consejo Económico y Social, Principles on the Effective Prevention and Investigation of Extra-Legal, Arbitrary and Summary Executions, E/Res/1989/65, 24 de mayo de 1989.

71 Manual sobre la Prevención e Investigación Eficaces en las Ejecuciones Extralegales, Arbitrarias o Sumarias, UN Doc. E/ST/CSDHA/.12 (1991).

72 Prevención de las violaciones de derechos humanos cometidas con armas pequeñas y armas ligeras, Sub-Com. Res. 2006/22 (2006). 
Esta revista forma parte del acervo de la Biblioteca Jurídica Virtual del Instituto de Investigaciones Jurídicas de la UNAM www.juridicas.unam.mx

DOI: http://dx.doi.org/10.22201/iij.24484873e.2017.149.11353

disposiciones legislativas y otras medidas internas eficaces para que las autoridades competentes realicen las investigaciones debidas en todos los casos de muerte sospechosa...", ${ }^{73}$ la respuesta a esta resolución no ha sido amplia. Si bien se han realizado seguimientos a las medidas preventivas, la Asamblea General ha enfatizado que las sanciones penales caen fuera de su ámbito de acción, dejándole a la CPI establecer dichas sanciones por la comisión de EESA. ${ }^{74}$

En segundo lugar, el Relator Especial en la materia ha tomado una postura similar. Dado que su mandato está limitado a la determinación de hechos y a funciones consultivas, proporcionar una respuesta penal a este fenómeno está más allá de su esfera de acción. ${ }^{75}$ Sin embargo, sí cae dentro de su mandato promover sanciones más enérgicas para las EESA, pero el Relator Especial sólo ha señalado problemas particulares que surgen en un momento específico. ${ }^{76}$

A pesar de estas limitantes, el trabajo del Relator Especial ha sido útil en identificar las tendencias mundiales que deben ser consideradas si se redacta un tratado universal. Estas conductas que merecen mención son: muertes debido al uso excesivo de la fuerza por agentes encargados de mantener el orden ${ }^{77}$ y la falla de detener las EESA. ${ }^{78}$

En tercer lugar, los instrumentos legales antes mencionados también fallan en proveer sanciones penales por las EESA. El Manual y los Principios de Armas Pequeñas abordan exclusivamente medidas de investigación

73 Asamblea General, Ejecuciones sumarias o arbitrarias, A/Res/42/141, 7 de diciembre de 1987.

74 Asamblea General, Ejecuciones extrajudiciales, sumarias o arbitrarias, A/Res/55/111, 12 de marzo de 2001; Asamblea General, Ejecuciones extrajudiciales, sumarias o arbitrarias, A/ Res/57/214, 25 de febrero de 2003; Asamblea General, Ejecuciones extrajudiciales, sumarias o arbitrarias, A/Res/59/197, 10 de marzo de 2005; Asamblea General, Ejecuciones Extrajudiciales, sumarias o arbitrarias, A/Res/61/173, 1 de marzo de 2007.

75 Consejo Económico y Social, Ejecuciones sumarias o arbitrarias, E/RES/1982/35, 7 de mayo de 1982. Para una guía general de las funciones del Relator Especial véase Ejecuciones extrajudiciales, sumarias o arbitrarias: folleto informativo núm. 11 (Rev. 1).

76 Consejo de Derechos Humanos, Informe del Relator Especial sobre las Ejecuciones Extrajudiciales, Sumarias o Arbitrarias, A/HRC/4/20 29 de enero de 2007. El informe se enfoca en conflictos armados, muertes misericordiosas, la definición de los "crímenes más serios" en la imposición de la pena de muerte y la prohibición de la pena de muerte preceptiva.

77 Consejo Económico y Social, Informe de la Relatora Especial sobre las Ejecuciones Extrajudiciales, Sumarias o Arbitrarias, E/CN.4/2002/74, 9 de enero de 2002, párr. 30-32.

78 Ibidem, párrs. 41-43. 
Esta revista forma parte del acervo de la Biblioteca Jurídica Virtual del Instituto de Investigaciones Jurídicas de la UNAM

y prevención. Sólo los Principios EESA incluyen ciertas recomendaciones para prevenir la impunidad, a través de sanciones penales. El principio 1 menciona: "Los gobiernos prohibirán por ley todas las ejecuciones extralegales, arbitrarias o sumarias y velarán por que todas esas ejecuciones se tipifiquen como delitos en su derecho penal y sean sancionables con penas adecuadas que tengan en cuenta la gravedad de tales delitos".

En conclusión, las EESA no han sido tipificadas a nivel internacional. Sólo los Principios EESA proporcionan cierto nivel de tipificación por estos actos al proveer que los Estados deben penalizar estas conductas e incluir el deber de extraditar o juzgar, así como una disposición para el uso de la jurisdicción universal. ${ }^{79}$ Sin embargo, dichos Principios no son un tratado, y su estatus como parte del derecho consuetudinario también es dudoso, como se evidencia por uno de los reportes anuales más recientes del Relator Especial. ${ }^{80}$

\section{La respuesta del derecho penal a la tortura y a la desaparición forzada}

En las secciones anteriores se mencionó que la tortura y la desaparición forzada usualmente son contempladas como violaciones graves a los derechos humanos; muchas veces cometidas junto con las EESA. ${ }^{81} \mathrm{El}$ objetivo de esta sección es dar un panorama general del marco jurídico de estos dos crímenes internacionales en un esfuerzo por comparar su regulación con la del DAV, incluida las EESA.

La Convención contra la Tortura y otros Tratos o Penas Crueles, Inhumanos o Degradantes (Convención contra la Tortura) $)^{82}$ penaliza la tortura a través del siguiente esquema:

79 Principios EESA, principio 18. Un enfoque similar a los Principios EESA también ha sido sugerido por Amnistía Internacional. Véase Programa de 14 Puntos para Prevenir las Ejecuciones Extrajudiciales, en http://www.amnestyusa.org/What_We_Fight_For/14_ Point_Program_for_the_Prevention_of_Extrajudicial_Executions/page.do? id $=1101188 \Xi^{2} n 1=2 \Xi^{2} n 2$ $=769 \Xi^{2} n 3=777$.

80 Asamblea General, Informe del Relator Especial sobre Ejecuciones Extrajudiciales, Sumarias o Arbitrarias, A/61/311, 5 de septiembre de 2006, 2006, párrs. 31 y 32. Incluso el Relator Especial ha reconocido la naturaleza no obligatoria de las normas de EESA pero enfatiza la utilidad como herramientas interpretativas.

81 TEDH, Timurtas v. Turkey, op. cit. y Corte IDH, Velázquez Rodríguez v. Honduras, op. cit.

82 Convención contra la Tortura y Otros Tratos o Penas Crueles, Inhumanos o Degradantes. 
Esta revista forma parte del acervo de la Biblioteca Jurídica Virtual del Instituto de Investigaciones Jurídicas de la UNAM

1. La Convención establece una definición de lo que se debe entender por tortura (artículo 1o.).

2. La Convención obliga a los Estados parte de "velar por que todos los actos de tortura constituyan delitos conforme a su legislación penal", añadiendo que esto incluye actos de tentativa, complicidad y participación (artículo 4.1).

Asimismo, instruye que se deben imponer penas severas a actos de tortura, debido a su "grave naturaleza" (artículo 4.2).

3. Los Estados también deben implementar la legislación necesaria para ejercer su jurisdicción, basada en los principios de territorialidad (artículo 5.1.a), personalidad activa (artículo 5.1.b) y personalidad pasiva (artículo 5.1.c).

4. Adicionalmente, establece una obligación de extraditar o juzgar las alegadas ofensas (artículo 5.2).

5. Finalmente, los Estados están obligados a prestarse mutuamente toda la asistencia necesaria para llevar a cabo el juicio (artículo 9).

Un esquema similar fue adoptado en la Convención Internacional para la Protección de todas las Personas contra las Desapariciones Forzadas (Convención contra la Desaparición Forzada). ${ }^{83}$

Hay tres aspectos donde existe una gran brecha en las regulaciones de la tortura y la desaparición forzada, y violaciones al DAV.

En primer lugar, no existe algún tratado internacional que penalice las violaciones del DAV. Hay algunas disposiciones de soft law en los Principios EESA, pero son normas de derecho consuetudinario en desarrollo que todavía no son vinculantes. En cualquier caso, la Convención contra la Tortura y la Convención contra la Desaparición Forzada fueron precedidas por declaraciones de Asamblea General, que ayudaron a desarrollar el marco consuetudinario para el procesamiento de estos crímenes internacionales y que fueron indicaciones claras de la voluntad de los Estados involucrados de homogeneizar la penalización de estos actos. ${ }^{84} \mathrm{~A}$ lo mucho, los Principios EESA pueden ser equiparados a las declaraciones que

83 Convención Internacional para la Protección de todas las Personas contra las Desapariciones Forzadas; véase también Wise Edward M. et al., International Criminal Law: Cases and Materials, New York, Lexis Publishing, 2000, p. 178. Este mecanismo también ha sido usado en varios tratados en material de terrorismo.

84 Declaración sobre la Protección de Todas las Personas contra la Tortura y Otros Tratos o Penas Crueles, Inhumanos o Degradantes, A/Res/3452 (XXX) 9 de diciembre 
Esta revista forma parte del acervo de la Biblioteca Jurídica Virtual del Instituto de Investigaciones Jurídicas de la UNAM

precedieron las Convenciones contra la Tortura y la Desaparición Forzada, que sólo pueden confirmar el hecho de que es necesario un tratado internacional que penalice las EESA.

En segundo lugar, los Principios EESA incorporan algunas de las características básicas de la respuesta del derecho penal a otras violaciones a derechos humanos; sin embargo, falta el elemento esencial de este esquema: una definición. La importancia de dicha omisión es crucial porque sin ella, el resto del esquema es inútil, ya que se vuelve imposible determinar a qué conducta o conductas aplica dicha disposición.

La falta de una definición ya ha causado confusión. El Relator Especial ha considerado que el genocidio y las matanzas durante un conflicto armado son parte de su mandato, pero estos casos, aunque involucran una violación al DAV, responden a otras preocupaciones. ${ }^{85}$ De la misma forma, la muerte a consecuencia de tortura también es considerada que forma parte de su mandato, pero se podría argumentar que en este caso la privación de la vida es una consecuencia del acto principal, que es la tortura en sí misma, así que debe ser estudiada en este contexto. ${ }^{86}$

No obstante, es importante señalar que usualmente una definición es difícil de conseguir y puede ser el último aspecto del marco legal que se desarrolle. Tal y como sucedió en el caso de la desaparición forzada. Su definición sólo se acordó en la redacción de la Convención contra la Desaparición Forzada y estuvo ausente en la Declaración de la Asamblea General.

En tercer lugar, los argumentos anteriores están basados en las EESA que son el aspecto más desarrollado en la penalización del DAV, pero por la misma razón, también están limitadas a ese aspecto particular de la privación de la vida. Sin embargo, el análisis de la jurisprudencia de derechos humanos saca a la luz el hecho de que este derecho puede ser violado de múltiples maneras, como evidencia la jurisprudencia de los órganos de derechos humanos. ${ }^{87}$

de 1975; Declaración sobre la Protección de Todas las Personas contra las Desapariciones Forzadas, A/Res/47/133, 18 de diciembre de 1992.

85 Consejo Económico y Social, Informe del Relator Especial sobre Ejecuciones Extrajudiciales, Sumarias o Arbitrarias, E/CN.4/2002/74, 9 de enero de 2002, párrs. 27-29 y $66-71$.

86 Ibidem, párrs. 33-35.

87 Véase sección 2. 
Esta revista forma parte del acervo de la Biblioteca Jurídica Virtual del Instituto de Investigaciones Jurídicas de la UNAM

7. ¿Qué hace falta?

Mientras que el DIDDHH aún mantiene ciertos aspectos del DAV como fundamentales, esta estimación no tiene reflejo en el DPI. Para que esto ocurra, es necesario un tratado multilateral integral, como las convenciones contra la Tortura y la Desaparición Forzada. Se propone que un esquema general de penalización como el implementado para la tortura y las desapariciones forzadas sea adoptado para las violaciones o privaciones del DAV. Con relación a los mecanismos procedimentales, se han tomado pasos importantes en los Principios EESA, pero no está claro a qué aplican, por lo que es esencial que se proporcione una definición. La base de la misma debe ser el desarrollo de los órganos de derechos humanos que han ampliado la aplicación del DAV a escenarios particulares y las tendencias identificadas por el Relator Especial que caen dentro del alcance de las violaciones del DAV.

La importancia de una definición (o un conjunto de conceptos) que claramente identifique violaciones al DAV también debe ser distinguida de otros crímenes, como el genocidio y ciertos crímenes de guerra, que corresponden a una estructura legal diferente, que protegen diferentes valores o derechos humanos, y para los que la muerte es sólo incidental al crimen. Lo anterior reafirmaría la importancia del DAV, que no debe depender de la regulación de resultados de otros crímenes internacionales.

Es importante esta distinción frente a crímenes internacionales, pero un tratado integral como el propuesto tendría de la misma forma consecuencias distintas internamente. Como se evidencia por los tratados y la jurisprudencia analizada, no todos los casos donde ocurre una violación al DAV son de relevancia internacional, por lo que la idea de tipificar el homicidio simple a nivel internacional debe descartarse. Esto lleva a la conclusión de que sólo ciertas violaciones del DAV son de preocupación internacional; éstas establecerían el alcance del homicidio internacional. En otras palabras, se propone que sólo los casos derivados del DIDDHH y EESA deben ser internacionalmente tipificados bajo el nombre de homicidio internacional. Así, la convención de homicidio internacional debe distinguir estos actos, de casos ordinarios de homicidio que caen fuera del ámbito de preocupación internacional y que deben ser sancionados libremente por cada Estado (si acaso). 
Esta revista forma parte del acervo de la Biblioteca Jurídica Virtual del Instituto de Investigaciones Jurídicas de la UNAM

Las convenciones contra la Tortura y la Desaparición Forzada tienen un propósito que va más allá de la obligación de tipificar conductas de relevancia internacional. También sirven para armonizar la tipificación no sólo a través de una definición general que debe ser la base de una definición penal en el ámbito interno, sino también la necesidad de especificar quién debe ser responsable. Adicionalmente, proveen ciertas salvaguardias contra la impunidad, como el establecimiento de jurisdicción, el deber de extraditar o juzgar, la obligación de proveer asistencia mutua y el deber de investigar y enjuiciar estos casos. Estas cláusulas necesitan ser especificadas en el caso del homicidio internacional, lo que enfatiza la necesidad de un tratado internacional que incluya todos estos aspectos.

En suma, las violaciones del DAV deben tener su propio marco jurídico. Por lo tanto, se sugiere el crimen de homicidio internacional. La definición propuesta es la siguiente:

A los efectos de esta convención, homicidio internacional se considera cualquier acto u omisión ilegal e intencional que cause la muerte a una persona, perpetrado por un agente del Estado o miembro de una organización paramilitar, milicia, escuadrón de la muerte o cualquier otro grupo patrocinado por el Estado.

Además, se deben añadir las siguientes cláusulas:

1) Cualquier persona que cometa, ordene, solicite o induzca a la comisión o tentativa de comisión, es cómplice o participe en un homicidio internacional. $^{88}$

2) Homicidio internacional incluirá la muerte causada por el uso irracional de la fuerza por parte de las fuerzas de seguridad, incluido miembros de la policía o del ejército.

3) Cuando la muerte sea resultado de tortura, tratos inhumanos o como consecuencia de secuestro, los Estados deberán considerarlo como circunstancias agravantes. ${ }^{89}$

88 Convención Internacional para la Protección de Todas las Personas contra las Desapariciones Forzadas, artículo 6 (b). También debe considerarse la responsabilidad de superior jerárquico.

89 Ibidem, artículo 7 (2)(b). Ya se considera como circunstancias agravantes cuando la muerte resulta de una desaparición forzada en relación a embarazadas, menores de edad, personas con discapacidad u otras personas particularmente vulnerables. 
4) Se presume que la muerte fue causada por un agente estatal o miembro de una organización paramilitar cuando se lleve a cabo durante su detención, custodia o sirviendo una pena de prisión. Lo mismo aplicará a las personas que estén en hospitales o instituciones mentales bajo la administración del Estado.

5) Cuando la muerte sea causada por un particular, el Estado está obligado a investigar, enjuiciar y sancionar a los responsables.

\section{GONCLUSIÓN}

El presente artículo fue escrito con dos objetivos: determinar la importancia del DAV en el DIDDHH y analizar la sanción a sus violaciones en el DPI.

En la primera parte, se sugirió que cada Estado en lo individual se encargue de las violaciones generales del DAV, puesto que sólo las muertes causadas por agentes estatales siguen siendo relevantes para la comunidad internacional, como se muestra en el desarrollo jurisprudencial de los diferentes órganos de derechos humanos.

Por lo tanto, uno esperaría que al menos estos casos fueran tipificados internacionalmente, pero no es el caso. Sin bien los tratados internacionales actuales abordan la privación de la vida a individuos, proteger el DAV no es el objetivo que los motiva. Sólo los Principios EESA proporcionan un esquema similar a la respuesta internacional a la tortura y desaparición forzada, pero este es sólo un instrumento de derecho internacional en desarrollo. Lo que se necesita es un tratado multilateral que tipifique al menos aquellas violaciones del DAV causadas por agentes estatales, ya que es el único aspecto claramente relevante en la comunidad internacional y que abarca las EESA, así como otras formas de muerte causadas por agentes estatales. 